\title{
Escenarios para la innovación de producto: Diseño, empresarialidad y políticas públicas
}

Amparo Álvarez Meythaler ${ }^{1}$

Rubén Méndez Reátegui²

Pontificia Universidad Católica del Ecuador, Quito ${ }^{3}$

RECIBIDO: 31.08.2016 / ACEPTADO: 01.04.2017

\section{Resumen}

El documento analiza cómo el Diseño interacciona con la empresarialidad, la innovación de producto y puede influir en la formulación de políticas públicas. Esta propuesta se desarrolló a partir de una amplia recopilación bibliográfica, a través de la cual se enfoca al Diseño como actividad proyectual desde aspectos como el espíritu empresarial y la creatividad. Estos aspectos resultan fundamentales cuando el objetivo consiste en la generación de inputs para el cambio de la matriz productiva y su marco legislativo. En específico, este documento desarrolla su propuesta a partir de información recabada de empresas ubicadas en Santiago de Chile. La revisión efectuada permitió establecer que el Diseño es una disciplina que facilita la gestión de procesos creativos dentro de la empresa. En el caso descrito se concluye que el Diseño se considera como una herramienta que contribuye con las pymes en el desarrollo de contenidos estratégicos que faciliten la labor del empresario de guiar procesos de agregación de valor que generen oportunidades de expansión y competitividad local y regional y, por lo tanto, requiere de reglas de juego que fomenten su expansión.

Palabras clave: diseño estratégico, valor agregado, empresarialidad y políticas públicas.

\footnotetext{
1 Mag. Ing. Amparo Álvarez Meythaler: Ingeniera en Diseño Industrial, Magíster en Diseño Avanzado por la Pontificia Universidad Católica de Chile. Investigadora en Diseño Estratégico, Gestión del Diseño en Empresas, Diseño y Gestión de Procesos de Innovación de Productos y Servicios y Diseño de Modelos de Negocio para Emprendimiento. Docente titular en la Pontificia Universidad Católica del Ecuador - PUCE (FADA). Correo electrónico: adalvarez@puce.edu.ec.

2 Doctor Rubén Méndez Reátegui: PhD en Economía por la Universidad de Macquarie y Doctor en Ciencias Sociales por la Universidad Rey Juan Carlos de España. Docente titular principal de la Facultad de Jurisprudencia de la Pontificia Universidad Católica del Ecuador. Académico visitante en la Universidad Complutense de Madrid, Universidad de Salamanca, Universidad de Málaga, Murdoch University y el Rotterdam Institute for Law \&amp; Economics. Ha realizado proyectos de investigación en áreas afines al contenido del artículo tales como Empresarialidad y Desarrollo Económico, Historia de la Empresarialidad, PYMES y Economía Formal, Innovación y Calidad Institucional. Correo electrónico: rcmendez@puce.edu.ec.
}

${ }^{3}$ Deseamos agradecer a nuestra colaboradora Camila Monserrate Cárdenas Sánchez, egresada de Ingeniería en Diseño Industrial por su valiosa ayuda. Correo: camila.m.cardenas.s@pucesa.edu.ec. 


\section{Scenarios for product innovation: Design entrepreneurship and public policy}

\section{Abstract}

This paper analyses how design interacts with the entrepreneurship and innovation of the product from an interdisciplinary perspective. This proposal was developed from extensive bibliographic research through which design is considered a projective activity from aspects such as entrepreneurship, creativity and public policy. These aspects become fundamental when the objective consists of the generation of inputs for change in the productive matrix through the institutional framework. In particular, this document develops its proposal stemming from information that was collected from companies located in Santiago, Chile. The revision that was done made it possible to establish that design is a discipline that facilitates the management of creative processes within a company. In the described case, it is concluded that design is considered a tool that contributes to SMEs in the development of strategic contents that facilitate the work of the entrepreneur in guiding added-value processes.

Keywords: strategic design, value added, entrepreneurship, public policy and public policy.

\section{Introducción}

Chile estableció sus estrategias en un intento por permitir el crecimiento de su economía al considerar el rol de la exportación de materias primas como la plata, la harina, el cobre y el trigo, y recibir a cambio productos manufacturados. Sin embargo, como respuesta al agotamiento de este modelo, surgió el desarrollo tecnológico, la modernización de la infraestructura y la apertura al comercio exterior (Meller, 1998). Este escenario rompió antiguos paradigmas reflejados en un modesto crecimiento económico y mostró cómo, a través de políticas de apertura, era posible alcanzar el progreso de la industria como una tendencia potencialmente estable en el largo plazo.

El cambio de rumbo también persiguió una redefinición del sector industrial a través del crecimiento cuantitativo de la producción y el aumento de la tasa de empleo (Larraín et al., 2000). El efecto inmediato fue permitir que la población destinara parte de sus ingresos a la compra de productos manufacturados en el país. ${ }^{4}$ Esto contribuyó con el renacimiento del mercado de consumo y se consideró como un ejemplo de progreso en Latinoamérica.

En la medida en que el desarrollo de la industria nacional vino de la mano con la apertura comercial al mercado exterior, significó mayor competencia para los agentes proveedores de bienes y servicios en el mercado, y se vio reflejada en la aparición de un amplio número de artículos que se ofertaron a precios diferenciados en comparación con la manufactura chilena tradicional caracterizada por su modesta presentación pero compensada por un mayor grado de confianza en el usuario. No obstante, esta mayor confianza en el producto nacional no constituyó un elemento de suficiente trascendencia que fuese capaz de compensar per se el prestigio y los precios reducidos que ofrecían las marcas foráneas (Eiras \& Flores, 2001).

\footnotetext{
4 A partir de la dinámica del comercio creciente, sale a la luz un nuevo "perfil de usuario" cada más exigente, que enfoca sus preferencias en atributos tales como la estética, la funcionalidad y la apropiación del objeto, es decir, del proceso de integración de creación de valor en el producto.
} 
Por lo tanto, la contraposición de los escenarios anteriormente descritos representó un cambio y supuso la consolidación de nuevos procesos que rompieron los tradicionales lineamientos de política económicocomercial y fue complementado por el ejercicio de la acción gubernamental de promoción a través de la aparición de sociedades públicas como Sociedad de Fomento Fabril (SOFOFA) desde 1883. Así mismo, este proceso resultó congruente con el paso hacia la modernidad, lo que permitió en Chile que surjan espacios que plasman el adelanto tecnológico-industrial como primer signo de innovación. A su vez, la formación de nuevas identidades y tradiciones culturales (Mosterin, 2009) que al amparo del proceso de mercado y un estado más eficiente, permitieron a la empresa privada surgir en un entorno que puede ser catalogado como el más abierto y competitivo en América del Sur. ${ }^{5}$

A partir de la interacción con la economía y la "empresarialidad", el artículo ubica al Diseño en el proceso de innovación de producto en escenarios de participación en el sistema productivo que impactan en la identidad y cultura de las pymes de la región Metropolitana de Santiago de Chile. Además, estudia el enfoque del empresario de ese país con relación a las oportunidades de captura de valor de un producto que incide en la percepción del usuario y cómo internaliza los procesos de innovación a estrategias productivas endógenas en la empresa.

El documento fue dividido en ocho secciones. En la segunda sección se presenta el caso de la pequeña y mediana empresa (pyme) en Chile. A continuación en la tercera se prosigue con una explicación de cómo la influencia de la globalización, ha incidido en las decisiones de estado materializadas a través de políticas públicas específicas. Posteriormente, en la cuarta sección se presenta el rol del diseño 6 y su relación con la pyme manufacturera chilena. La sexta sección ha sido destinada a discutir las nuevas formas de competitividad e individualidad en la pyme chilena sección se prosigue con una discusión sobre cuando surgió la necesidad de innovar en Chile. En la séptima sección se presentan las orientaciones para la innovación en la pyme chilena. Finalmente, en la octava sección se presentan las conclusiones del documento. ${ }^{7}$

\section{La pequeña y mediana empresa (pyme) en Chile}

La búsqueda de beneficios económicos que permitan mantener equilibrios claves a la empresa en el largo

\footnotetext{
5 Tanto en el país como América Latina se vivencia al mismo tiempo signos de cultura de premodernidad, modernidad y posmodernidad, incentivada por el flujo de comunicaciones y medios informáticos que han obligado a construir una definición propia en la empresa basada no solo en el territorio sino en redes internacionales que han hecho de la pyme un constructo versátil en una cultura global.

${ }^{6}$ Se debe indicar que para el Diseño el concepto producto designa al conjunto de bienes y servicios producidos por una organización. El mismo requiere cumplir con requisitos básicos en función del campo de aplicación del mismo. Sin embargo, si se amplía el concepto de productos de Diseño al sumar a los bienes de consumo otros productos que van más allá de lo material como son el branding de lugares o de ocio, e incluye dentro de su concepción de la Cultura del Diseño ámbitos que aparentemente pudieran parecer ajenos a ella, como el marketing, la publicidad y la comercialización. Según Viladás (2008), el Diseño como disciplina cumple tres funciones críticas cuando se integra en la empresa: identifica valor, confiere valor y comunica valor, en la medida que sea percibido por el usuario. El Diseño se ocupa de hacer visible al producto y efectiviza la comunicación del mismo.

${ }^{7}$ Se debe indicar que para el Diseño el concepto producto designa al conjunto de bienes y servicios producidos por una organización. El mismo requiere cumplir con requisitos básicos en función del campo de aplicación del mismo.
} 
plazo, y la optimización de recursos asignados para la elaboración de productos (Ardichivili et al., 2003), tienen un alto nivel de valoración por parte de los usuarios y su relación costo-beneficio propone un precio de venta conveniente.

En ese sentido, para el empresario, ${ }^{8}$ el logro de condiciones productivas y comerciales que generen un escenario favorable mercantil tiene una relación directa con la dimensión de valor agregado como un elemento que incide en las preferencias del usuario y eleva la competitividad y fidelidad del mismo. Así, según sostiene Álvarez, (2015), la mayor preocupación del empresario en Chile se centra en el desenvolvimiento comercial del producto y en el financiamiento del capital del trabajo.

En particular, para el empresario chileno, el problema de innovación se encuentra íntimamente vinculado al nivel de ventas y costos que alcanzan sus productos. Asimismo, los empresarios han mostrado sus preferencias por la introducción de estrategias ${ }^{9}$ basadas en la calidad como elemento de valor agregado que determina la preferencia y fidelidad del cliente. Entonces, se deduce que el empresario chileno entiende y valora la innovación como un cambio inherente a la estructura productiva, que permite dar cuenta de las transformaciones sustanciales de la empresa como la renovación de maquinaria, incorporación de distintas tecnologías, cambios de infraestructura, entre otros aspectos. Además, está consciente de que necesita algo más que los diferencie de la competencia y se relacione íntimamente con el producto ya sea por la misma tipología de objetos a través de los años o por la disminución notable de órdenes de trabajo (CORFO, 2007). Por tal motivo, se ha vinculado la generación de valor con la fidelidad del usuario y la identidad del producto (Nickerson, 2007). La idea de otorgar valor agregado ${ }^{10}$ para el empresario resulta de crear productos que respondan a ciertos requerimientos funcionales, uso y estéticos para el usuario, con la mínima inversión (Stam, et al., 2006). Por lo tanto, el núcleo de innovación de la PYME está dado en un sector industrial manufacturero que busca perfeccionar el producto mientras aumente la aceptación de los usuarios (Tabares, 2012), quienes son los responsables de determinar la estabilidad de la empresa frente la competencia.

Las pequeñas y medianas empresas en Chile personifican uno de los sectores de la economía que ha sido sujeto de instrumentos y programas especiales de apoyo generado por el Estado como agente protagonista del macroentorno. ${ }^{11}$ Durante los últimos años, un volumen importante de recursos estatales se ha destinado, por ejemplo, a programas de asistencia técnica y programas de fomento productivo e innovación para este grupo de empresas (Dini \& Stumpo, 2002; Poblet \& Amorós, 2013), pero con un alcance aún exiguo para cubrir todas las necesidades de cada sector.

\footnotetext{
${ }^{8}$ El empresario como ser humano que dirige un entorno productivo en búsqueda de nuevas oportunidades y que al estar inmerso en este proceso se relaciona impacta favorablemente en los intereses en un entorno societal y permite aproximar la solución desde el núcleo de cualquier cambio o transformación importante en la empresa (Fu Lai Yu, 1999; Ardichvili et al., 2003).

9 En este documento el concepto de estrategia alude a los lineamientos, directrices y actividades de mejora que utilizan la organizaciones o entidades para lograr diferenciarse de sus competidores y obtener productividad en el presente y asegurar su sustentabilidad en el futuro. Por lo tanto, la estrategia se encuentra relacionada a acciones de sobrevivencia y crecimiento.

10 En el presente documento valor agregado es definido como aquellos atributos físicos perceptibles del producto.

${ }^{11}$ A partir de un enfoque mainstream, en Chile, a la fecha se han propuesto o establecido distintos mecanismos de estímulo para la creación y fortalecimiento de las pymes. Uno de ellos, llamado Estatuto PYME (Ley 20.416), que introdujo un dispositivo especial para las denominadas Empresas de Menor Tamaño (EMT).
} 
El establecimiento de grupos de protección para sectores donde se fomentó la participación estatal bajo el objetivo de mantener una alta productividad ha significado el uso de mecanismos que pretendieron impulsar al sector de las pyme; sin embargo, también ha ocasionado la formación de gremios y asociaciones que se han constituido como grupos de presión (Álvarez \& Vergara, 2007). La pyme en Chile representa el 17\% de la distribución por tamaño del sector, cifra importante pues la incidencia en aporte económico, comercial y desarrollo sectorial que generan este tipo de empresas prevalece frente a distintos sectores de la economía. Existen alrededor de 157.779 empresas pyme registradas en Chile, un 52\% que corresponde a 82.045 empresas se ubica en el sector manufacturero (Tercera ELA, 2015). En las medianas industrias tan solo el $5,7 \%$ de sus ventas se destinan a exportaciones, cifra que se reduce a un $1,2 \%$ en el caso de las pequeñas industrias, lo cual las hace vulnerables a los ciclos de economía nacional hasta la actualidad.

En ese sentido, el seguimiento del proceso de evolución de las pymes, permite observar una tendencia hacia la desaparición de las empresas manufactureras en Chile que no han sido capaces de hacer frente a los efectos de la globalización y en consecuencia adaptarse a las tendencias de cambio en el mercado chileno, abierto a una marcada internacionalización (Olivares, 2005). Esto se ha reflejado en la tasa de salida de pymes que, aunque fue alta durante "la Depresión" de principio de los años ochenta al alcanzar hasta un $40 \%$, también fue considerablemente alta en el período de mayor expansión económica chilena, que se desarrolló entre los años 1986 y 1997 y posteriores.

Se infiere, entonces, que las empresas que funcionan en contra de la corriente de globalización están destinadas a salir del mercado, gran parte del resultado está condicionado entre la sobrevivencia y el crecimiento de las empresas (Gandoy et al. 2014). De este modo, la probabilidad de que una pyme sobreviva aumenta con su tamaño y su edad que además refleja un nivel de conocimiento adquirido sobre el proceso de mercado (Acedo \& Florín, 2006). ${ }^{12}$ Por eso en Chile, muchas empresas emergentes fracasan más que las empresas grandes y las empresas pequeñas que sobreviven crecen más rápido pero con bajo nivel de impacto en el mercado.

Varios estudios realizados por el Departamento de Economía de la Universidad de Chile para el año 2010 sobre el análisis de ventas, concluyen que la actividad de venta en la pyme corresponde a un $8 \%$ de casi un tercio de las empresas que engloba el sector económico (Chile C. d., 2010). Al margen de los porcentajes, dentro del entorno se evidencia un peso fundamental que tiene el comercio en Chile con el creciente número de empresas de comercialización minorista (retai). El Diseño desde este enfoque, inmerso en una cadena de distribución y comercialización, ha creado una nueva cultura de consumo más personalizada y una notable modificación en los hábitos de consumo, así ha otorgado importancia al proceso integral de venta, de modo que: la comunicación, distribución y presentación de un producto al mercado se han convertido en estrategias inherentes de la empresa.

\footnotetext{
12 Las pymes manufactureras son sistemas que se mueven en torno al producto y su importante ventaja es la versatilidad y flexibilidad para lograr innovaciones (García \& Martínez, 2009). A la vez, son capaces de tomar decisiones rápidamente y comunicar fácilmente dichos aprendizajes, estas y otras cualidades que han reconocido a las pequeñas empresas como versátiles, dinámicas, creativas y adaptables han logrado que se beneficien de múltiples créditos y financiamientos al encontrarse en la mira de programas de fomento productivo (Boscherini \& Yoguel, 1996).
} 


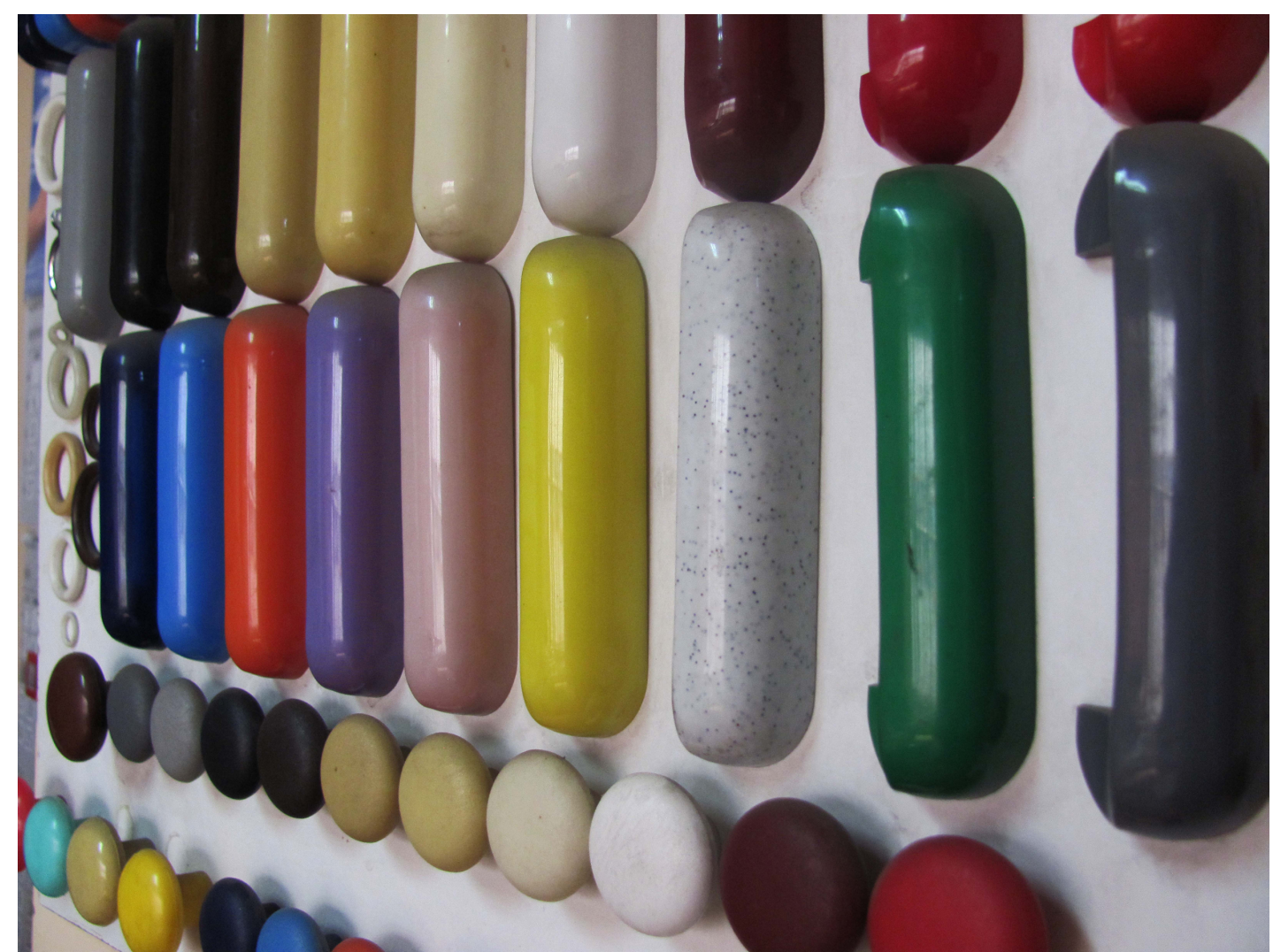

Fig. 1. Pérdida de valor agregado en comodities.

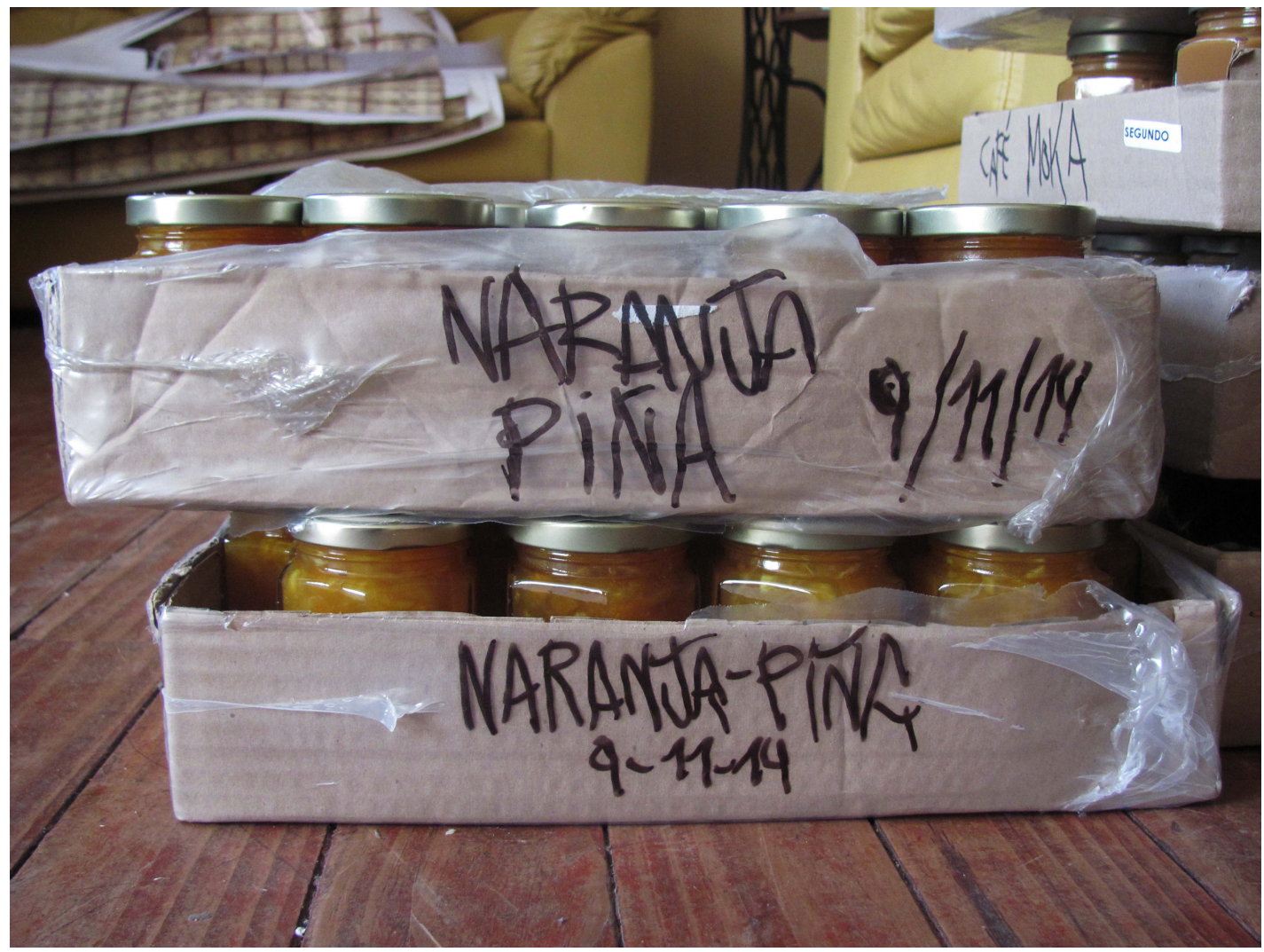

Fig. 2. Presentación de productos al mercado. 
Asimismo, surgieron empresas emergentes denominadas "industrias creativas" 13 que se han expandido de una manera viral por todo el territorio y que de forma espontánea han originado un nuevo paradigma de generación y gestión del conocimiento. El Diseño se utiliza como una herramienta estratégica de transmisión del know how en diferentes fases del proceso productivo, convirtiéndose en una fortaleza inherentes frente a su competencia, además, facilita la conexión con empresas de diversa índole mediante actividades auxiliares como publicidad, gráfica, fotografía, entre otros, que ha tomado más fuerza y generado impacto en el mercado nacional. Este crecimiento acelerado pone en evidencia la importancia del Diseño y la generación de nuevo conocimiento dentro de los procesos productivos.

Entonces, proyectar el Diseño en la pyme confiere valores y carga simbólica y de significado al producto fuera del proceso de manufactura, apropiándose del espacio de contacto entre el producto y el usuario para establecer una experiencia de vinculación de nuevo orden, constituyéndose en un transmisor de valores, historia, signos, símbolos, cultura (Viladás, 2010, p. 26). En ese sentido, el Diseño se considera un recurso estratégico que toma aristas como forma, función y valor, simplificándolos hasta convertirlos en un relato, para fortalecer y conservar los vínculos y relaciones entre producto-usuario.

\section{Globalización y cambio en la gestión de la política pública}

La globalización influenció el cambio de rumbo en la gestión de la política pública chilena con impacto directo en los aspectos macroeconómicos. Este cambio se enfocó en el establecimiento de una mayor apertura comercial: el Acuerdo de Complementación Económica (ACE), ${ }^{14}$ el AAP (Acuerdo de Alcance Parcial) ${ }^{15}$, el AAE (Acuerdo de Asociación Económica), ${ }^{16}$ los ALC (Acuerdos de Libre Comercio) ${ }^{17}$ y los TLC (Tratados de Libre Comercio) ${ }^{18}$. A través de ellos, Chile logró el establecimiento de veintidós (22) acuerdos que involucraban a cincuenta y nueve (59) países, lo que amplió su acceso al $62 \%$ de la población mundial, es decir, aproximadamente 4 mil millones de habitantes. Dichas medidas lograron estabilizar paulatinamente el crecimiento económico pero sin concebir una proyección estable futura en términos de capacidad exportadora, lo cual ha generado recientemente controversia e incertidumbre.

\footnotetext{
${ }^{13}$ Se entiende como industria creativa a un sector particular creciente en Chile que nace y se nutre del territorio que lo sustenta, donde quienes trabajan lo hacen muchas veces por vocación, por lo que las remuneraciones y ventas no necesariamente reflejan el beneficio real que las actividades creativas generan (CNCA, 2014).

14 Acuerdos bilaterales que los países latinoamericanos contraen entre sí con el objetivo de abrir recíprocamente sus mercados de bienes. Estos acuerdos se inscriben en el marco jurídico de la Asociación Latinoamericana de Integración (ALADI).

${ }^{15}$ Acuerdos comerciales básicos, enfocados principalmente en materias arancelarias para un grupo de específico de bienes. A través de estos acuerdos se pueden liberar o rebajar los aranceles de algunos de los productos del comercio entre los países que lo negocian y se les concibe como una primera fase en un proceso de apertura más amplio a largo plazo.

${ }^{16}$ Acuerdos con un alcance similar a los TLC pero que además incluyen materias del ámbito político y de cooperación. Un ejemplo lo constituye el Acuerdo de Asociación que existe entre Chile y la Unión Europea.

${ }^{17}$ Acuerdo comercial regional o bilateral que busca ampliar el mercado de bienes y servicios entre los países participantes.

${ }^{18}$ Acuerdo de carácter comercial que se enfocan en establecer una zona de libre comercio que facilite la libre circulación de bienes, servicios y capitales, mediante una armonización de políticas y normas jurídicas. Se rigen por las reglas de la Organización Mundial de Comercio (OMC) o por mutuo aquellas de acuerdo entre los países participantes.
} 
Esto se condice con la asunción que concibe al libre comercio y la libre circulación de bienes como condicionantes que atañen a la mayoría de las pymes que han buscado alcanzar posicionamiento y expansión internacional (Larraín \& Vergara, 2002), al originar que la competencia por precio sea cada vez más intensa dada con propuestas de producto proveniente del extranjero. Además, se ha optado por no introducir masivamente políticas de protección y fomento productivo sino medidas de de autoajuste lo que ha generado que las pymes batallen por mantenerse en un nivel aparentemente estable frente a su competencia (Bell \& McNaughton, 2000; DIRECON, 2013). ${ }^{19}$

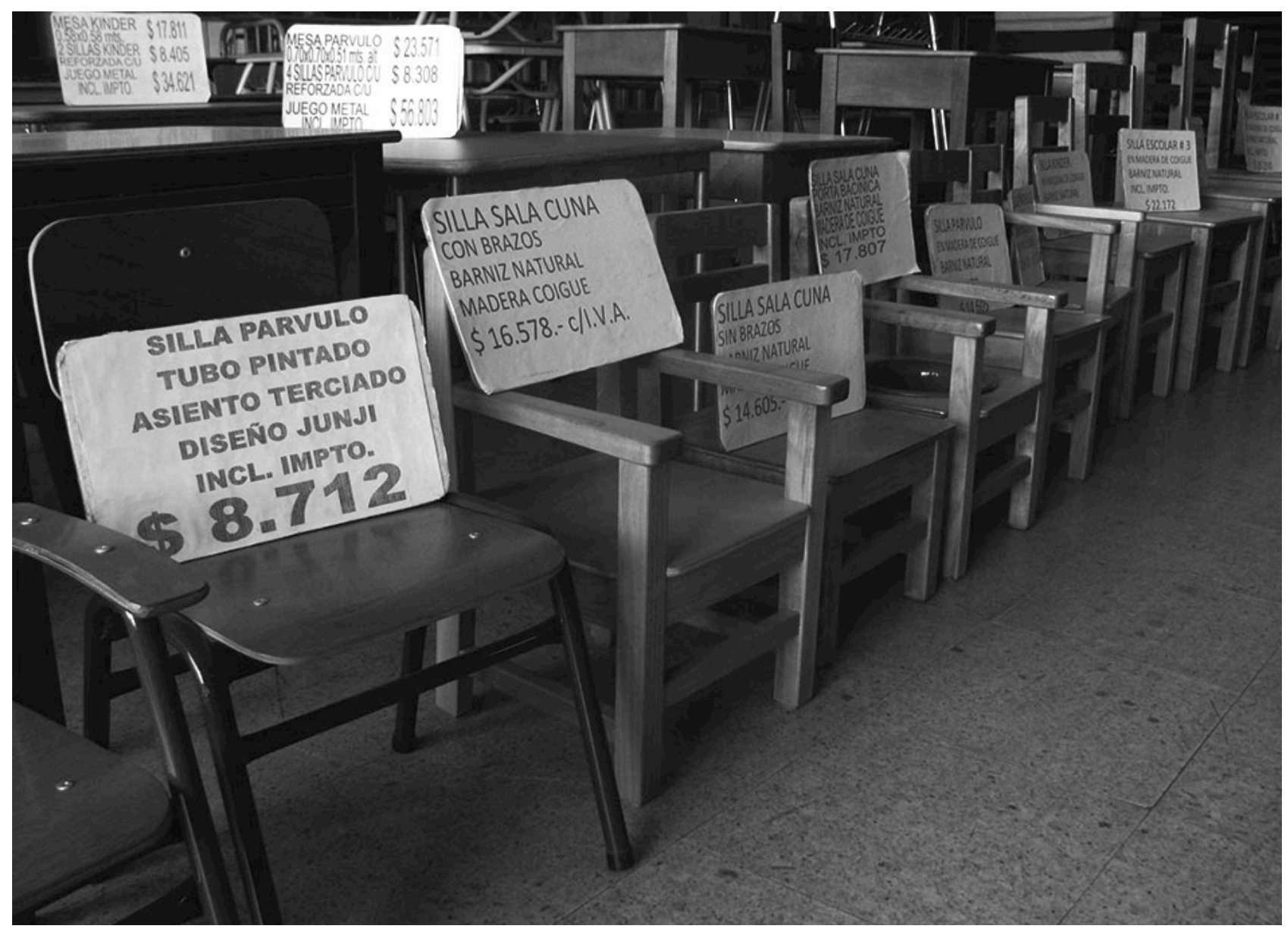

Fig. 3. Precio y circulación de mobiliario escolar.

La estabilidad económica y empresarial que generó dicha fidelización es lo que las pymes tratan de mantener como resultado de una simbiosis cultural que les ha permitido demostrar por muchos años la trascendencia de la misión de la empresa, pero, visibilizar calidad es cada vez más difícil en el sector productivo manufacturero (Manolava et al., 2002), por ello las pymes al reconocer la necesidad de buscar nuevos conocimientos y tendencias se tecnificaron y mejoraron sus procesos. Esto requirió de mayor inversión para alcanzar presencia internacional.

\footnotetext{
${ }^{19}$ A partir de un modelo mainstream de política sectorial (para la introducción de incentivos en el mercado), en Chile se decidió el establecimiento de agencias como CORFO la cual debe enfocarse en brindar facilidades de certificación hacia la gestión de calidad como las ISO 9001 y así intentar afianzar desarrollo del sector de las pymes.
} 


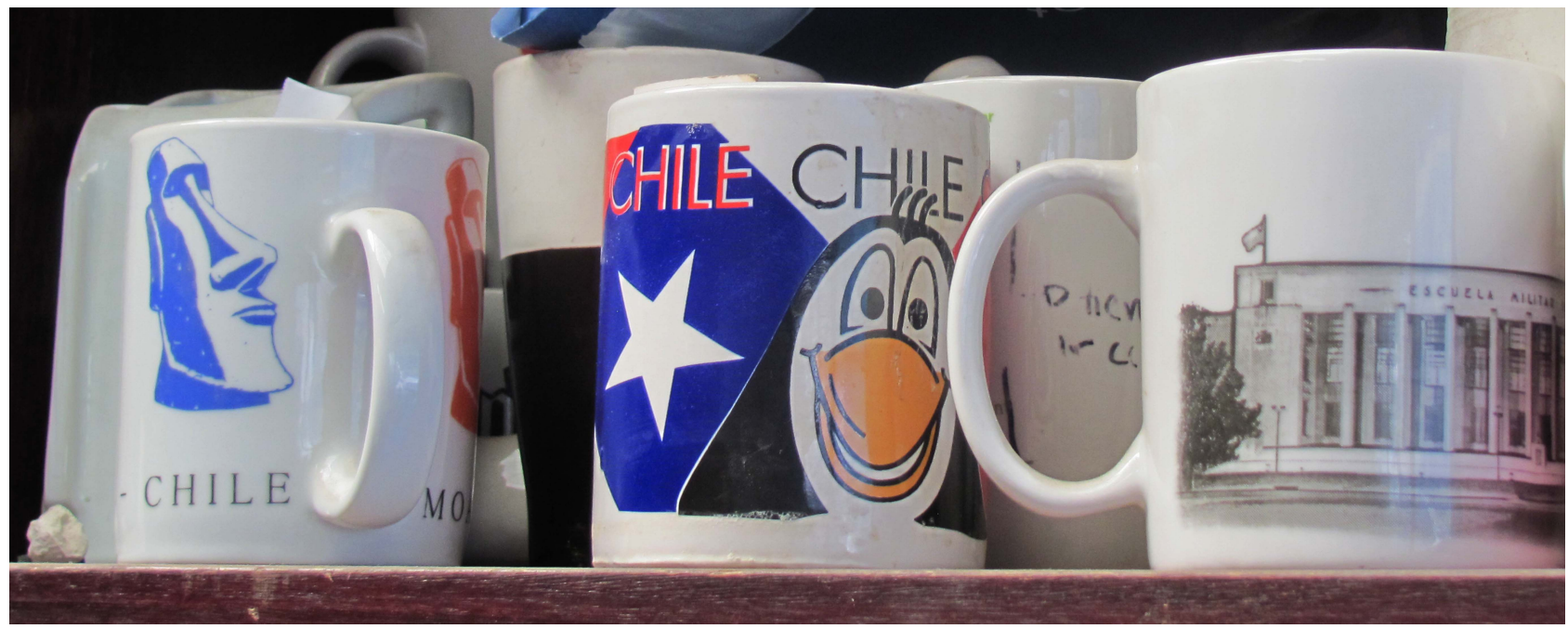

Fig. 4. Fidelización y promoción para el usuario El Diseño como Estrategia.

Para Méndez (2013), la evolución humana está marcada por la innovación, y esta se expresa mayormente dentro de un entorno donde prima la cultura de la libertad. Esto permite que las empresas a través de los clústers $^{20}$ puedan enfocarse en funciones específicas dentro de la cadena de valor de oferta de producto/ servicio.

Un ejemplo lo constituyen las empresas estadounidenses, que componen los referentes más innovadores. Según el Stanford Research Institute (SRI), estas han generado una corriente de cambio que ha impactado incluso a nivel gubernamental. Esto es así, pues los gobiernos profundizaron en el reto de establecer un ambiente más favorable para los negocios a través de la promoción de la innovación como factor dinamizante y generador de mayor competitividad productiva.

Abordar estratégicamente el Diseño parte por generar cambios medulares en prácticas de la educación, por lo que se proponen metodologías que se instalan como técnicas innovativas para reinventar el ecosistema de aprendizaje formal a una transformación más abierta y generadora de conocimiento, estableciéndose en universidades como Stanford University, Politécnico di Milano, University of Brighton, entre otras. Estás técnicas en torno al diseño como Design Thinking, Design Council, Design Service, Desing Doing han incidido en la educación en los últimos diez años en Chile. ${ }^{21}$

\footnotetext{
20 Se hace referencia al término de clúster por abordar la pyme desde el desarrollo industrial, entendiéndose como el grupo de industrias o establecimientos industriales que operan entre si de una manera precisa. Concepto popularizado por Porter (1990) y utilizado en los últimos años como instrumento de política industrial, que representa una forma de organización sólida que ofrece ventajas en términos de eficiencia, eficacia y flexibilidad como lo enuncia el mismo autor.

${ }^{21}$ A pesar de ser objeto de crítica desde una perspectiva teórica ajena a una visión mainstream de la gestión de la acción colectiva, se pueden nombrar "instrumentos" como la Ley de Creación de Empresas en un Día, Ley de Reemprendimiento, Capital Abeja, Semana de la pyme, Día de la Compra Pyme, Sernac Financiero, Ley I+D, entre otros.
} 
El proceso de elaboración de un producto manufacturado debe considerar el costo de oportunidad de los materiales y procesos. El mismo en el caso de la pyme chilena corresponde a un $95 \%$ del costo final de producción con una incidencia del $30 \%$ en expresada en términos del precio final del producto. Una interpretación de los datos expuestos llevo a la DUOC (2011) sostener que el costo del diseño de un producto corresponde únicamente a un $5 \%$ de su producción.

A razón de estos porcentajes para una pyme es muy difícil sobrevivir sin perseguir el cambio, está consciente que la competencia a nivel experiencial sobre sus habilidades productivas e innovativas ya no son fuentes estables para el crecimiento y sostenibilidad empresarial. Por esta razón, la pyme está en constante búsqueda de dinámicas que aumenten su competitividad, lo que-trae consigo la necesidad de renovación constante de estrategias para permanecer en el mercado (Vargas et al., 2010; Gandoy et al., 2014).22
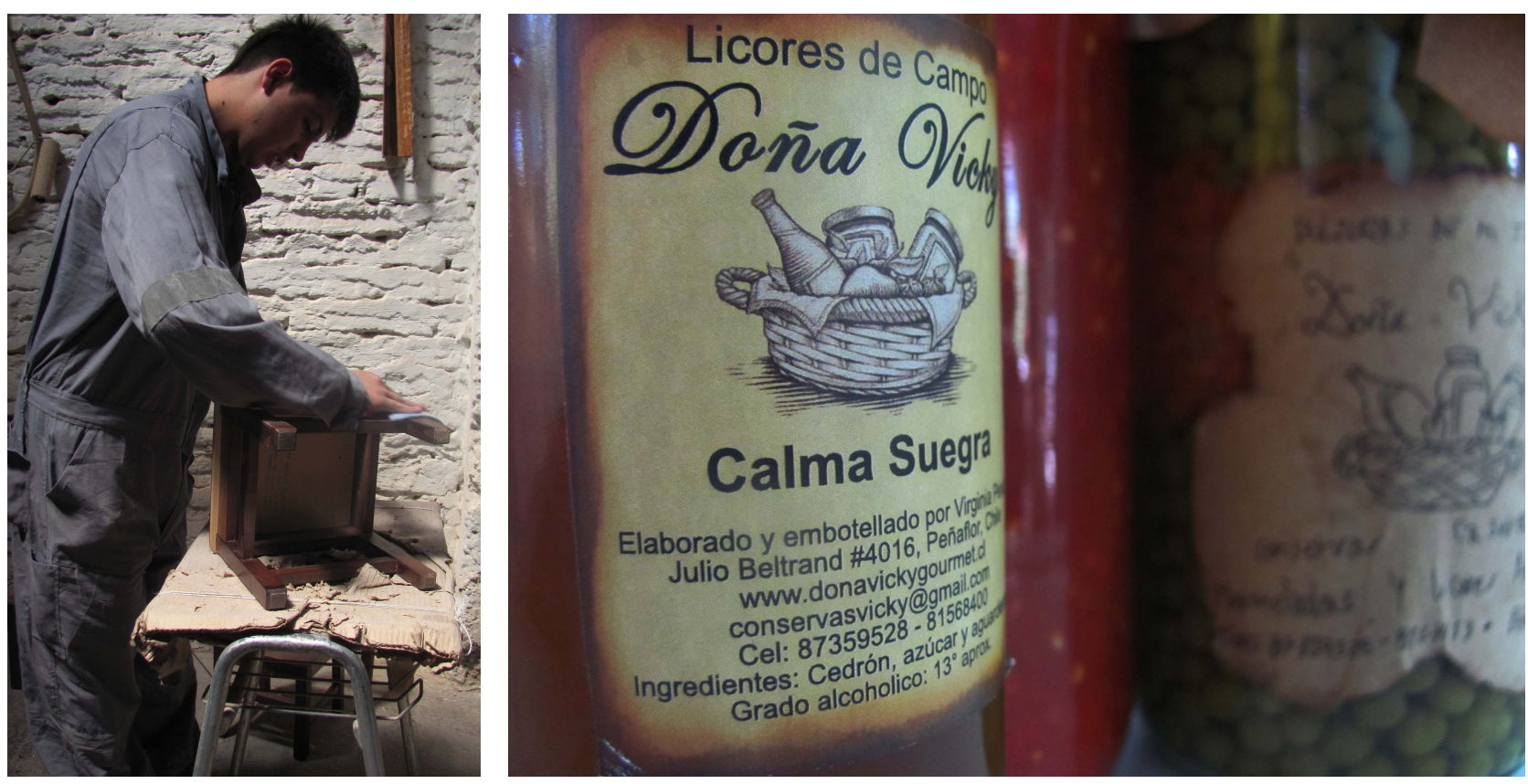

Fig. 5. (Izq.) Manufactura en la pyme chilena.

Fig. 6. (Dcha.) Promoción de productos en el mercado.

En el ámbito del Diseño la innovación implica potenciar la competitividad empresarial tal como ha sido instituido por las economías más desarrolladas. Esto requiere a su vez del fomento a la investigación y la elaboración de productos que permitan una rápida respuesta a necesidades especificas por parte del usuario (además de reforzar la identidad cultural). Lo expuesto confirma que los diseñadores no son ajenos al manejo de modelos de negocio y a la necesidad de establecer una visión con características particulares. Finalmente, esta afirmación se corrobora por la acción de estructurar y gestionar el proceso de diseño, que se inicia por la valoración como un elemento estratégico que facilita posicionarse y diferenciarse de la competencia.

\footnotetext{
22 La mayoría de las empresas manufactureras en Chile, construyen estrategias competitivas para alcanzar el liderazgo en costos, y por consiguiente sus esfuerzos innovadores están orientados a la reducción en el uso y costo de materiales para lograr optimizar el proceso de producción (Alarcón, 2012).
} 


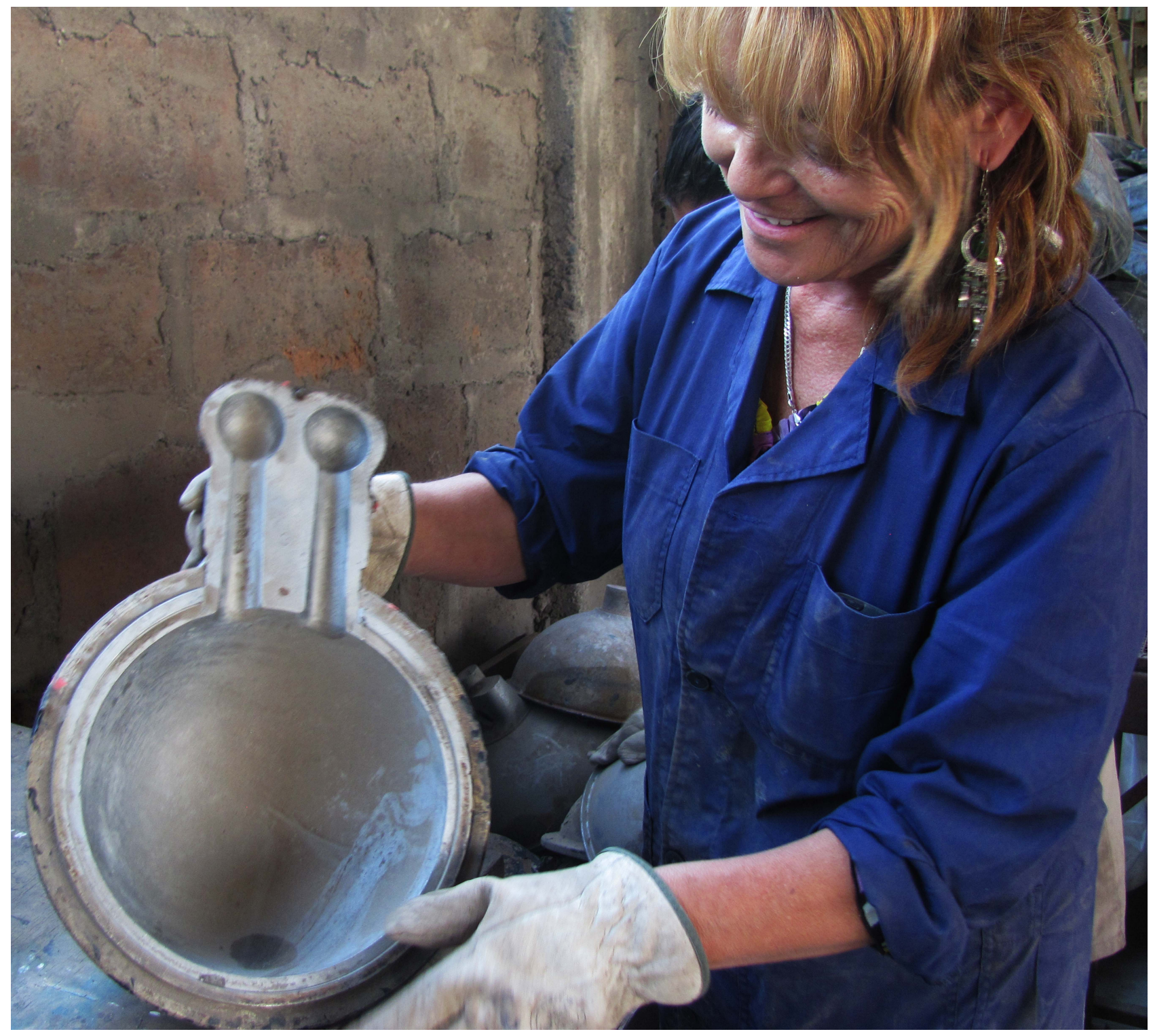

Fig. 7. Apropiación del producto.

Según Kotler (2006), a nivel macro empresarial impulsar el Diseño requiere mecanismos de acción colectiva expresados a través de políticas públicas de carácter proactivo que fortalezcan la gestión del Diseño y del proceso de mercado. Este tipo de propuestas debe conjuntamente permitir que los distintos tipos de innovación en las pymes sean implementados de manera eficiente. En esta misma dirección, la gestión del Diseño también implica la comprensión y administración efectiva de macroentornos y microentornos que requiere un discernimiento in extenso de las características del sector en el que tendrá incidencia (Finizio, 2002).

En respuesta a este escenario se han creado redes de fomento para diversos sectores productivos como: Comisión Nacional de Investigación, Científica y Tecnológica (CONYCIT), Corporación de Fomento de la Producción (CORFO), Programas de Fomento de Exportaciones Chilenas (PROCHILE), Fundación para la Innovación Agraria (FIA), Instituto de Desarrollo Agropecuario (INDAP), Servicio Agrícola y Ganadero (SAG), Servicio de Cooperación Técnica (SERCOTEC), Asociación de Exportadores Manu- factura (ASEXMA), 
Sociedad de Fomento Fabril (SOFOFA), entre otros; que a través de financiamientos y capacitaciones a sectores productivos del país han sido propuestas como una alternativa de política pública proactiva (Verdugo, 2004; Cobin 2006).

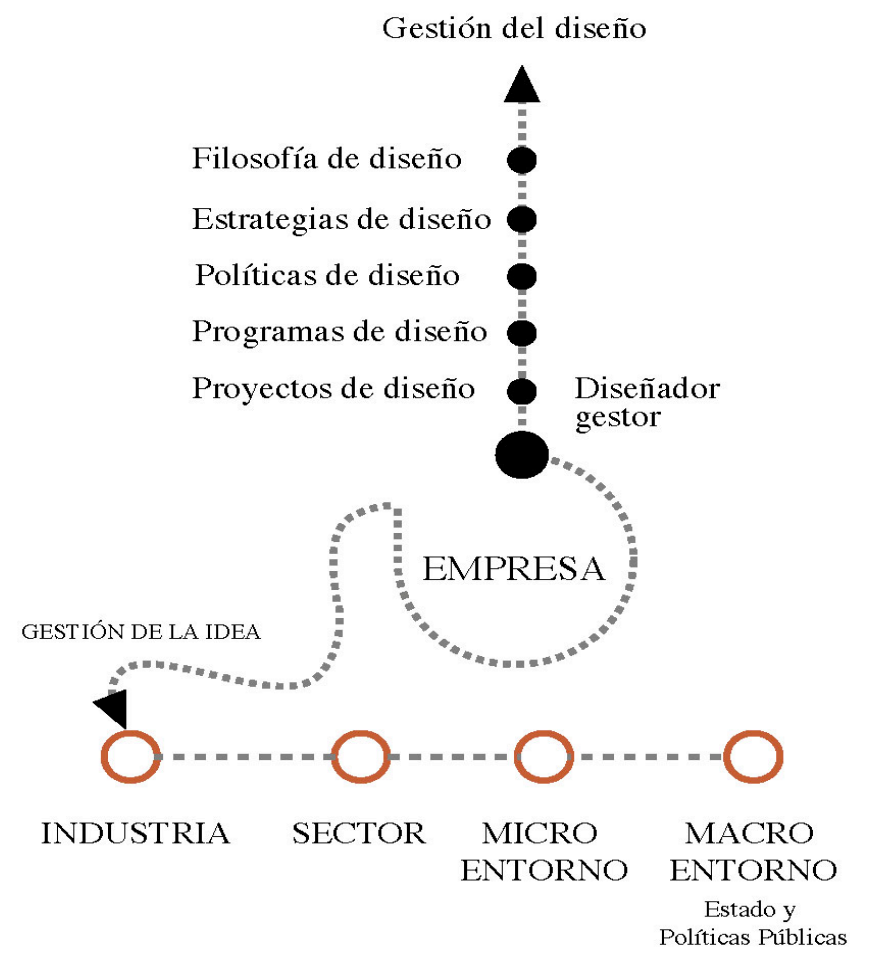

Gráfico 1. Guía esquemática del Discurso sobre la Gestión de la Idea (Finizio, 2002).

Se puede concluir entonces que, promover el Diseño a través de la gestión de la idea puede ser uno de los escenarios ideales para introducir conceptos de innovación y estudiar a las pymes chilenas desde la necesidades de la acción colectiva expresada por medio de políticas públicas reactivas y proactivas enfocadas en alcanzar el mayor desarrollo posible del sector manufacturero.

\section{Identidad e Individualidad en la pyme chilena}

La identidad es un constructo abstracto que resulta de la adaptación del ser humano ante los cambios acelerados de la sociedad (Hall, et al.1996). Esto requiere de la incorporación de deseos, tradiciones, necesidades, experiencias, en función de las cuales se modela una identidad específica, es decir, un conjunto de patrones o signos distintivos particulares además de criterios y contenidos que inciden en la aparición de las estrategias asumidas tanto por empresas como por agentes adscritos a la sociedad civil. A partir de esta proposición se puede establecer que aspectos como la identidad se corresponden a una construcción cultural (e incluso lingüística) que evoluciona de manera espontánea visualizándose en los productos (Alonso \& Garcimartin, 2007; Méndez, 2013). Esta postura es relevante debido a que la persona que constituye una empresa, transforma la realidad pasada, sea experiencial, cultural o social y la traduce a un significado propio, que sumado a la modernidad del sector forman diversos códigos sociales. 
En ese sentido, la lógica de la individualidad se basa en una formación personal de conceptos a través de experiencias y conocimientos, es decir, una relación de causa y efecto que se da en la toma de decisiones, que al final construyen el perfil del empresario y se reflejan en la cultura de la empresa para formar una identidad colectiva (Viladás, 2008). Es decir, a nivel empresarial, hablar de identidad organizacional se relaciona a la existencia de identidades colectivas que actúan simultáneamente influenciadas por la cultura de la empresa (Topa \& Palací, 2005) y delinean otras actitudes y conductas diferentes que hacen de cada empresa un ecosistema único dentro del sector. Todas las identidades mencionadas hacen alusión al ser de la empresa construida cognitivamente en un entorno cambiante, formándose y adaptándose a tendencias sociales, políticas y económicas, que forjan la construcción de una nueva identidad estratégica bajo los enfoques de individualidad y temporalidad (Grant et al., 2013).

La individualidad hace que la empresa construya una identidad estratégica basada en la diferenciación, que considera dimensiones clave en el proceso de Diseño (Viladás, 2010). Esta lógica de trabajar desde la identidad permite actuar en aspectos emocionales del ser humano para conducir el proceso de innovación hacia la ideación de productos con mayor significado para la empresa y el cliente.

Así, según explica Álvarez (2015) el empresario considera a la innovación como un proceso de transformación altamente riesgoso, al entender el riego en términos de costo, materia prima, tiempo, entre otros, por lo que hablar de innovación en la pyme es un tema que genera inseguridad.

La creciente tendencia a la innovación se da actualmente en programas que incentivan introducir nuevas competencias desde una perspectiva de Gestión de la Empresa. Sin embargo, el nivel de innovación en el producto aún es mínimo, y se evidencia en el bajo índice en ventas (INE, 2013).

\section{INDUSTRIA CHILENA}

Prendas de vestir excepto calzado

Productos de cuero y sucedáneos

Calzado excepto de plástico

Madera y accesorios, excepto los que son principalmente metálicos

Objetos de barro, loza y porcelana

Productos diversos derivados del petróleo y carbón

Equipo profesional y artículos oftálmicos

Maquinaria, aparatos y accesorios eléctricos

Otras industrias manufactureras

\section{VENTAS 2013}

$2,01 \%$

$\mathbf{0 , 3 8 \%}$

$1,39 \%$

$0,69 \%$

$\mathbf{0 , 2 2} \%$

$1,13 \%$

$0,12 \%$

$1,25 \%$

$\mathbf{0 , 1 9 \%}$

Gráfico 2. Índice y producción de ventas físicas (INE, 2013).

En relación a lo expuesto, el sistema de Apoyo a la Creación de Valor en la Empresa MESO (Mollenhauer \& Hormazabal, 2012), desarrollado en Chile, identificó que dentro del país surgieron intereses académicos, técnicos y públicos por la "empresarialidad", que la describieron como un fenómeno eminentemente creativo que permitió la renovación del tejido productivo en el cual se admite que las MIPYMES estén involucradas como líderes de las nuevas iniciativas de organismos públicos y privados. 
El Estado, en su afán de incentivar la innovación en la empresa chilena, identificó también que el problema con la productividad en las pymes se debió a su origen y a las dimensiones MESO del que se demostró la aparición de nuevos atributos y lenguajes en torno al producto como: la identidad, el relato, el valor, el significado y el modelo de negocio, que han sido poco perceptibles y estudiados, pero que resultan de gran impacto para elevar el índice de ventas en el país.

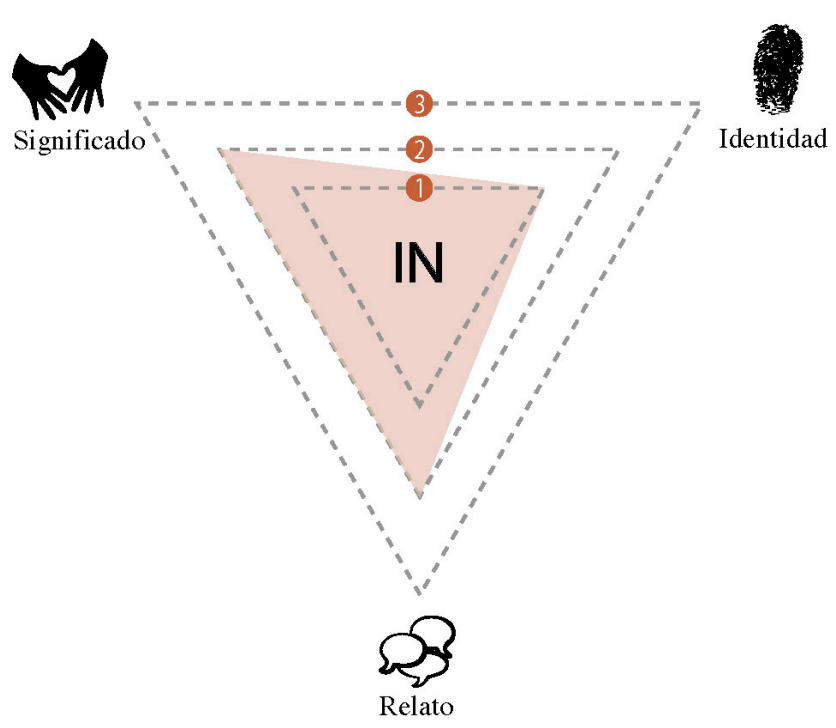

Gráfico 3. Dimensiones MESO en la PYME manufacturera chilena.

Por lo tanto, según Álvarez (2015), se infiere que la mayor parte de la versatilidad de la pyme, está ligada a la tecnología desde el proceso de manufactura, con el objetivo de aumentar volumétricamente la cantidad de producción por un período de tiempo y satisfacer la demanda, este modo de innovación constante y estático ha tenido el propósito de maximizar las ventas para responder a grupos masivos y a una sola necesidad (Macmillan, 2006).23 La diversidad de códigos y lenguajes nuevos para este sector productivo, se incorporan al mismo ritmo en el que la corriente de innovación entra en la empresa, con la aprobación y seguridad emocional del empresario al desarrollarse en un entorno donde puede asumir actitudes propositivas y de dominio, (Álvarez, 2015), lo cual se cimienta en reconocer y obtener el máximo valor de un mismo producto como oportunidad de expansión en el mercado. ${ }^{24}$

\footnotetext{
${ }^{23}$ Rampino (2011) menciona nuevas terminologías ligadas a los lenguajes modernos que describen al objeto con otras variables de innovación como, nueva tecnología en manufactura ejecutada no en el proceso sino en la usabilidad y experiencia, la satisfacción del usuario que resulta del nacimiento de nuevas demandas, tecnologías hacia un producto existente y necesidades del usuario, resultan ser una suerte de nuevas oportunidades de manufactura dentro del sector productivo.

${ }^{24}$ El engranaje que conjuga componentes en torno al producto posee un sistema de relación entre materias primas, tecnologías, canales de comunicación, procesos y recurso humano, que por varios años les permitió acercarse a los usuarios apoyados por las ventajas de fidelización ganadas aparentemente sólidas y estables, surgen las siguientes preguntas, ¿Necesita la pyme innovar? ¿Por qué el Diseño está obligado a dar cuenta del vínculo relacional de estos nuevos lenguajes en la pyme manufacturera?
} 


\section{Competitividad y Oportunidades para la pyme chilena}

En Chile se analizaron las empresas que mayores aportes han efectuado en términos de innovación en el país. ${ }^{25}$ Se estableció que 18.133, es decir, el 74\%, realizaron innovación tecnológica. Un 47\%, innovación en producto, y un $56 \%$, en proceso. Además, se identificó que persiste un déficit en innovación concentrado en ámbitos como marketing y gestión del producto (Ministerio de Economía, 2013). Esto datos deben ser contextualizados a partir de lo expuesto por Rampino (2011), quien menciona que las nuevas terminologías ligadas a los lenguajes modernos, que describen al objeto con otras variables de innovación como nueva tecnología en manufactura ejecutada no en el proceso sino en la usabilidad y experiencia (satisfacción del usuario), resultan del nacimiento de nuevas demandas y necesidades. Es decir, un nuevo espacio para alcanzar el desarrollo manufacturero dentro del sector productivo.

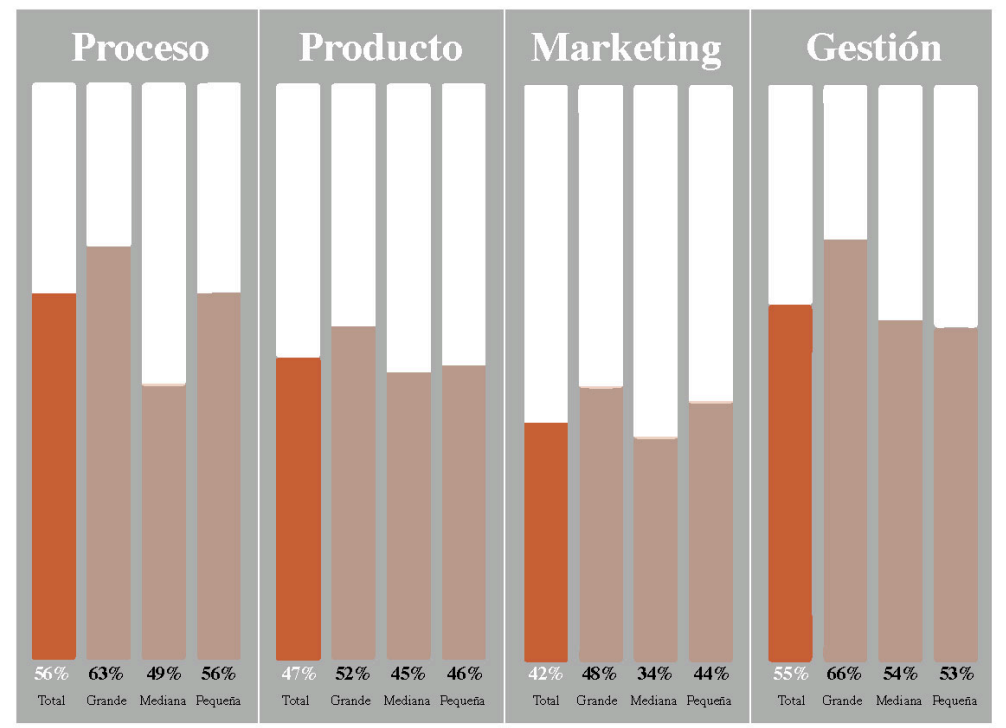

Gráfico 4. Aportes en innovación de empresas chilenas (Ministerio de Economía, 2013).

Por otra parte, a partir de la revisión del informe INNOVACIÓN (2015) se puede establecer que son las grandes empresas quienes lideraron los tipos de innovación, lo cual todavía resulta preocupante para una economía que tiene como objetivo la democratización y expansión de la actividad productiva.

La mayor parte de estos datos estadísticos muestran una realidad cuantitativa de las empresas que describen velocidades innovativas más que habilidades y capacidades de invención que están detrás (Ministerio de Economía, 2013b). Todos estos datos apuntan a que el ecosistema innovador en Chile está en una misma sincronía guiada por el entorno social y político y pasa por una suerte de transición guiada por la voluntad más que por necesidad. En ese sentido, Pastene (2013) puntualiza que: "a pesar del acceso a financiamientos, información de mercado, entre otros, tiene que ver con los cambios culturales, por ejemplo el hecho de que en Chile, fracasar sea mal visto".

${ }^{25}$ Se ha establecido que un $19 \%$ han realizado "innovaciones" entre el año 2009 y 2010, de ese porcentaje, un $16 \%$ de pymes innovan. Este índice para la pequeña empresa no es menor; sin embargo, la aceptación de un nivel alto de innovación radica en el desarrollo de varios tipos de innovación simultáneos. 


\begin{tabular}{|c|c|c|c|c|}
\hline & \multicolumn{4}{|c|}{ TAMAÑO DE LA EMPRESA } \\
\hline REALIZA INNOVACIÓN & Pequeña & Mediana & Grande & Total \\
\hline SI & 16.924 & 4.615 & 2.837 & 24.377 \\
\hline & $16 \%$ & $31 \%$ & $39 \%$ & $19 \%$ \\
\hline NO & 88.017 & 10.046 & 4.380 & 102.442 \\
\hline & $84 \%$ & $68 \%$ & $61 \%$ & $81 \%$ \\
\hline TOTAL & $\mathbf{1 0 4 . 9 4 1}$ & $\mathbf{1 4 . 6 6 1}$ & $\mathbf{7 . 2 1 7}$ & $\mathbf{1 2 6 . 8 1 9}$ \\
\hline
\end{tabular}

Gráfico 5. Séptima Encuesta de Innovación en Chile (2015).

\section{Proyección del Diseño de producto}

EI MINECOM, en el año 2012, hace un análisis sobre las oportunidades de emprendimiento e innovación en Chile. En este análisis, se exponen datos de interés sobre lineamientos de innovación promulgados a nivel nacional. Además, se destaca que, para llegar alcanzar el proceso de internacionalización, es necesario que los agentes productivos privados introduzcan el Diseño como parte de las actividades innovativas de una empresa (MINECOM, 2012) que les permita elevar la competitividad a nivel local y nacional.

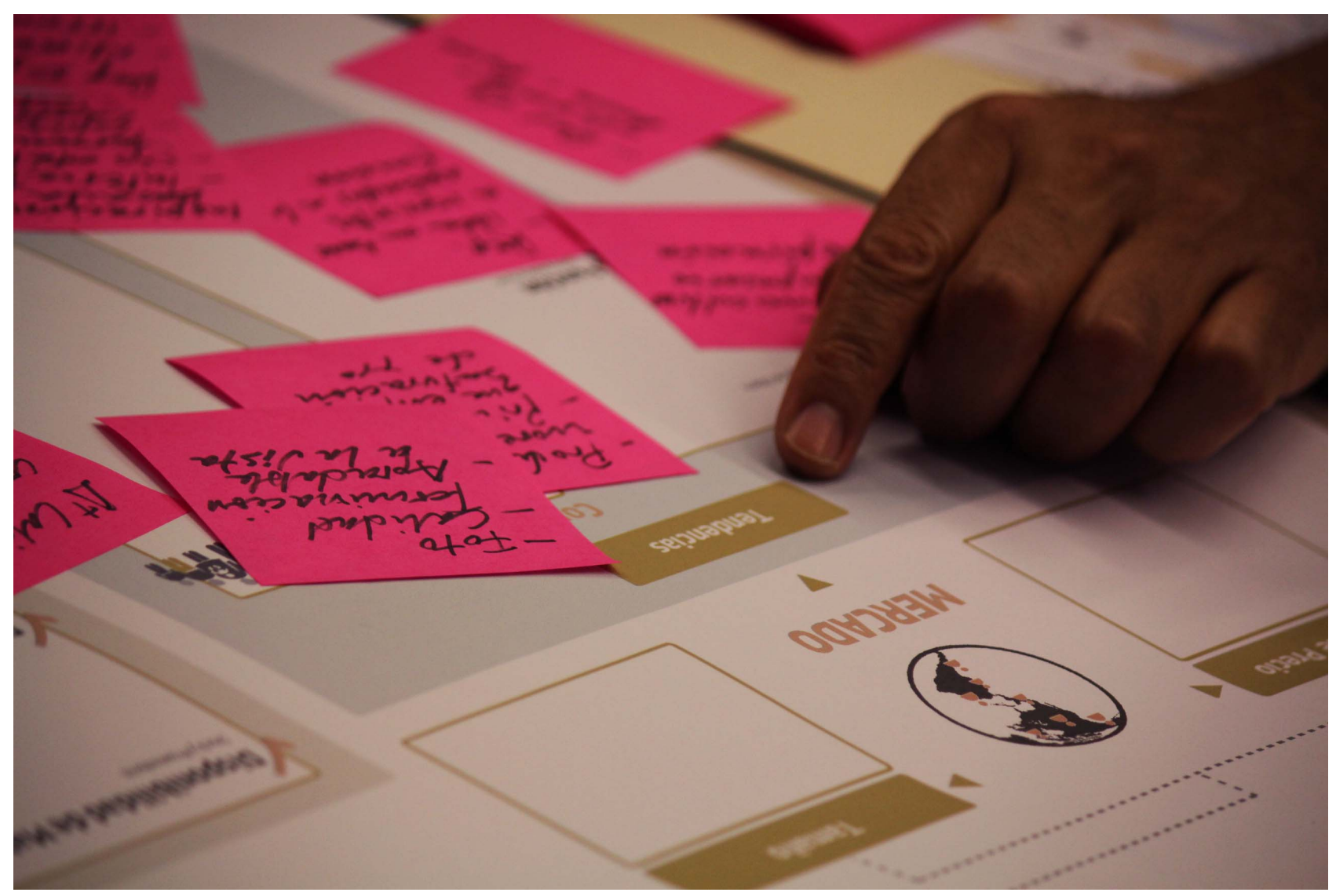

Fig. 8. Comprensión del mercado. 
Además se expone un dato interesante de la Séptima Encuesta de Innovación realizada por el Ministerio de Economía de Chile, en el que muestra que solo el Diseño tiene un retorno del $100 \%$ de la inversión sobre la empresa a pesar de su baja participación. Por lo tanto, resulta posible inferir que el Diseño constituye un activo importante para una empresa que desea aumentar su margen de rentabilidad.

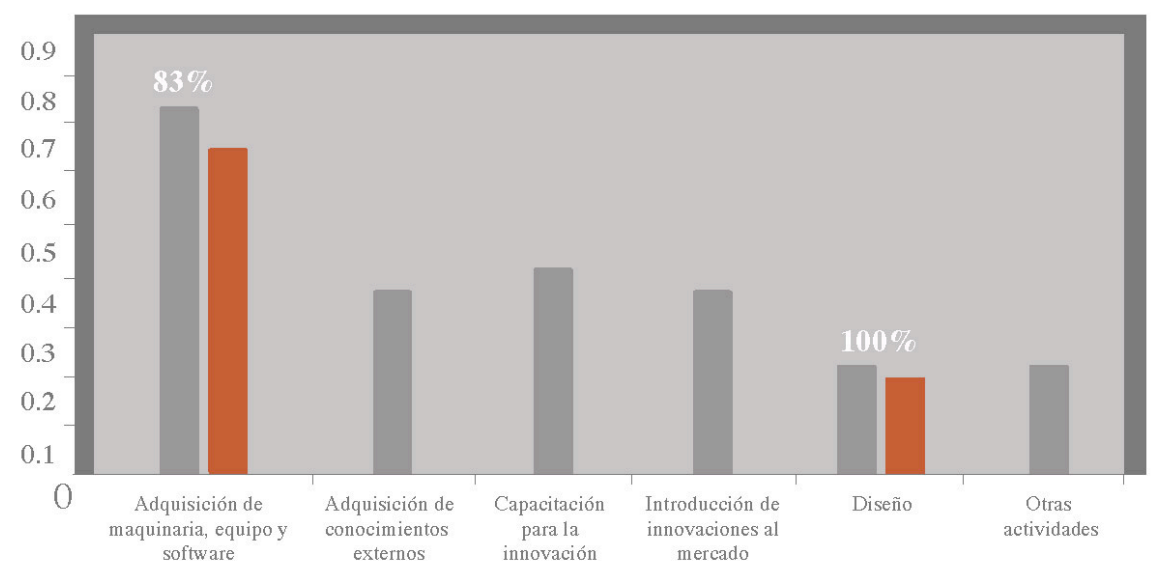

Gráfico 6. Novena Encuesta de Innovación MINECOM (2013-2014).

A partir de la contribución de Rampino (2011 y con la finalidad de identificar el nivel de innovación de la pyme con respecto a su producto pueden utilizarse los Cuatro Resultados del Proceso de Innovación del design-driven. Estos permiten establecer las características esenciales que debe tener un objeto innovador y alcanzar una visión general del nivel de innovación adquirido por un producto.

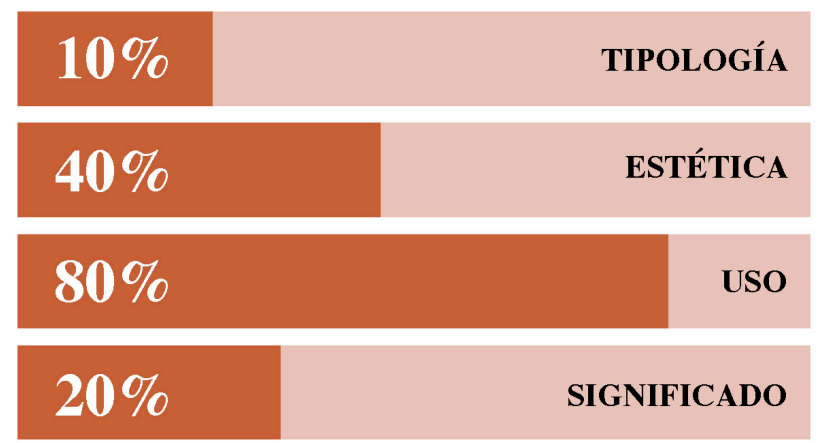

Gráfico 7. Cuatro Resultados del Proceso de Innovación design-driven en pymes chilenas.

\section{Conclusión}

La economía chilena se vio favorecida por el proceso de apertura comercial que impactó en su desarrollo y facilitó el cambio a nivel tecnológico-industrial. Además, incidió en la ruptura de paradigmas y constreñimientos culturales que limitaban la instalación de nuevas identidades. Este cambio identitario permitió que el espíritu empresarial de las pymes chilenas se consolide. Sin embargo, el recorrido todavía es largo cuando el objetivo implica el establecimiento de estrategias que persigan ampliar beneficios en el mercado más seguro para ellos. Esta dinámica generará nuevos productos solo cuando un usuario lo solicita (Álvarez, 2015). 
Es importante fomentar el Diseño a través de la gestión de la idea. Esto representa uno de los escenarios más favorables para introducir conceptos de innovación en el producto y establecer una nueva visión a partir del desarrollo de contenidos estratégicos. Esto tiene como finalidad facilitar la labor del empresario como mentor capaz de guiar el proceso de agregación de valor en el producto.

Por otra parte, el proceso de agregación de valor debe efectuarse de una manera creativa, que promueva oportunidades de reinvención y adecuación al mercado supeditado por la demanda. En este sentido, el Diseño se convertirá en una herramienta que expresa su importancia en un contexto social vinculado a elementos como la innovación y la creatividad como escenario que refleja la capacidad y aptitud inherente a los seres humanos de crear, producir, generar valor, y resolver problemas en una forma original. Estos elementos resultan propios del espíritu empresarial y se reflejan a través de la materialización del producto. Entonces, aplicar el Diseño desde una perspectiva subjetiva y conceptual potencia un plan estratégico e incide en el establecimiento de una nueva identidad reflejada a través del producto y en la cultura de la empresa.

Al contextualizar la anatomía de la pyme, el empresario debe efectuar múltiples actividades de gestión de la empresa. Es decir, el empresario busca descodificar la información que recibe del entorno en favor del producto y con base en un proceso de ensayo y error conexo (Álvarez, 2015). Sin embargo, subsiste el riesgo de generar objetos carentes de valor en innovación (Mollenhauer \& Hormazabal, 2012).

Por lo tanto, innovar en la generación de productos elaborados por las pymes es una oportunidad que permitirá potenciar el impacto social del desarrollo económico en Chile. Lo expuesto cobra mayor relevancia si se consideran estudios que identifican la necesidad de introducir al Diseño en las fases productivas por su alta capacidad para promover el retorno de una inversión. Igualmente, comprender esta premisa implica dilucidar cuáles serán los cambios que se dan en el entorno y de qué forma estos transmiten información útil para mantenerse al día en tema de tendencias de desarrollo de productos con valor.

\section{REFERENCIAS}

ÁlVAREZ, A. (2015). ID+C Apoyo a la Innovación de Productos. Servicios de Innovación basados en Diseño para la pyme. Santiago de Chile: PUC Chile.

ÁLVAREZ, R. \& Vergara, S. (2007). Sobrevivencia de pymes en Chile: ¿Ha cambiado a través del tiempo?, ¿Difiere por industrias?, Banco Central de Chile Documentos de Trabajo 427.

ACEDO, F. \& Florín, J. (2006). An entrepreneurial cognition perspective on the internationalization of SMEs. Journal of International En- trepreneurship, 4, 49-67.

ALONSO, J. (1994). "El proceso de internacionalización de la empresa", Información Comercial Española, $n^{\circ}$ 725, enero, pp. 127-143.

AMAL, M. y Rocha, A. (2010). Internationalization of small and medium-sized enterprises: a multi case study. European Business Review, 22 (6), 608-623. 
ARDICHVILI, A., Cardozo, R., \& Ray, S. (2003). "A theory of entrepreneurial opportunity identification and development". Journal of Business venturing, 18(1), 105-123.

BELL, J. y McNaughton, R. (2000). "Born global" firms: a challenge to public policy in support of internationalization. Marketing in Global Economy, 176-185.

BOSCHERINI, F. y Yoguel, G. (1996). "La capacidad innovativa y el fortalecimiento de la competitividad de las firmas: el caso de las pymes exportadoras argentinas". Documento de Trabajo No 71, Oficina de la CEPAL, Buenos Aires, Argentina.

CACHANOSKY, J. C.(1994). Historia de las Teorías del valor y del precio. Revista Libertas, 20, 22-44.

COBIN, J. M. (2007). Biblia y Gobierno, Lima: Instituto de Libre Empresa.

DINI, M., \& Stumpo, G. (2002). Análisis de la política de fomento a las pequeñas y medianas empresas en Chile (No. 136). United Nations Publications.

EIRAS, A. I., \& Flores, T. (2001). Los beneficios específicos de un tratado de libre comercio entre Chile y Estados Unidos. Heritage Foundation.

FINIZIO, G. (2002). Design \& Management. Gestire l'idea. Milano: Skira.

FORMICHELLA, M. (2004). El concepto de emprendimiento y su relación con la educación, el empleo y el desarrollo local. Buenos Aires, Argentina.

FU-LAI YU, T. (1999). "Entrepreneurial Alertness and Discovery”. The Review of Austrian Economics, 14:1, 47-63.

GANDOY, R., Díaz-Mora, C. and Córcoles D. (2014). "Una vía de internacionalización para las pymes más capaces: la inserción en redes de producción”, Información Comercial Española, 878, 131- 148.

GARCÍA, D., MARTÍNEZ, M., (2009) “Innovación y Cultura Empresarial de las MIPYME”, Universidad Autónoma de Aguascalientes y Universidad Politécnica de Cartagena. Aguascalientes: México.

GRANT, Kathryn E., Straker, Karla, Muller, Celeste, \& Wrigley, Cara (2013). The search for individualism: Self-expression through product personalisation.The International Journal of Designed Objects, 6(1), pp. 17-29.

HALL, S., Held, D., Hubert, D. \& Thompson, K. (1996). Modernity: An Introduction to Modern Societies, Wiley-Blackwell. JARILLO, J. y Martínez, J. (1991). Estrategia internacional. Más allá de la exportación, Madrid: McGraw-Hill.

JENSEN, M. C., \& Meckling, W. H. (1994). Teoría de la empresa: La gerencia: costes de agencia y estructura de la propiedad. En La naturaleza económica de la empresa ( 261-286). Madrid: Alianza Editorial.

KIRZNER, I. M. (1998a). "El Empresario”, Revista Libertas, 29, 1-22.

KIRZNER, I. M. (1998b). Competencia y Empresarialidad. Madrid: Unión Editorial.

LARRAÍN, F. \& Vergara, R. (2002). La transformación económica chilena entre 1973-2003, Santiago de Chile: Biblioteca Nacional de Chile. 
LARRAíN, F., Sachs, J. D., \& Warner, A. M. (2000). "A Structural Analysis of Chile's Long-Term Growth: History, Prospects and Policy Implications". Recuperado de http://www.earthinstitute.columbia.edu/sitefiles/file/about/director/ pubs/Chile 012000.pdf.

LAWSON, B., SAMSON, D, (2001). "Developing Innovation Capability in Organization", International Journal of Innovation Management, 5(3), pp. 1-23.

MACMILLAN, S. (2007). “Added value of good design”, Building Research \& Information, 268.

MANOLOVA, T. S., BRUSH, C., EDELMAN, L., \& GREENE, P. (2002). Internationalization of Small Firms: Personal Factors Revisited. International Small Business Journal, 20(1), 9-31.

JIMÉNEZ MARTíNEZ, I. (2007). Determinantes para la internacionalización de las pymes mexicanas. Análisis Económico, 22 (49), pp.111-131.

MELLER, P. (1998). Un Siglo de Economía Política Chilena (1890-1990). Santiago: Editorial Andrés Bello.

MÉNDEZ, R. (2013). "An Introduction to Institutional Coordination as An Alternate Model for Neo-Institutional Economic Analysis". Procesos de Mercado Revista Europea de Economía Política, 10(2), 151-200.

MITTELSTRAS, J. (2011). “On Transdisciplinarity”, Trames, 15, vol. 4, pp. 329-338.

MISES, L. V. (2010 ). La Acción Humana: Tratado de Economía. Madrid: Unión Editorial.

MOLLENHAUER, K., \& HORMAZABAL, J. (2012). “Clusters Innovativos en un Territorio”. Revista Diseño, 2.

MOSTERIN, J. (2009). La Cultura Humana, Barcelona: Espasa Libros.

NICKERSON, J. A., SILVERMAN, B. S., \& ZENGER, T. R. (2007). The 'problem'of creating and capturing value. Strategic Organization, 5 (3), 211-225.

OLIVARES, A. (2005). La globalización y la internacionalización de la empresa: Es necesario un nuevo paradigma? Estudios Gerenciales(96), 127-137.

PAUNOVIK, Z., \& PREBEZAC, D. (2010). Internationalization of small and medium-sized enterprises. Trziste, 22 (1), 57-76.

PLÁ BARBER, J., y SUÁREZ ORTEGA, S.M. (2001). “¿Cómo se explica la internacionalización de la empresa? Una perspectiva teórica integradora", ICADE Revista de las Facultades de Derecho y Ciencias Económicas y Empresariales, vol. 52 (Enero-Abril).

PLAZAS, R. (2015). "La marca registrada en Colombia; Ventajas del protocolo de Madrid”. Revista Republicana, 12 , 133-144.

POBLETE, CARLOS, \& AMORÓS, J.E. (2013). Determinantes en la Estrategia de Internacionalización para las pymes: el Caso de Chile. Journal of technology management \& innovation, 8 (1), 97-106.

RAMPINO, L. (2011). The Innovation Piramid: A Categorization of the Innovation Phenomenon in the Product-Design Field. International Journal of Design Vol. 5 Nro 1. 
ROJAS, S. \& VEGA, R. (2013) Los procesos de internacionalización en las pymes: reflexión desde las diferentes perspectivas. Poliantea IX, (16), pp. 53-70.

SHACKLE, G. (1996) The Nature of Economic Thought, Selected Papers, New York Cambridge: University Press, p. 130.

STAM, E. I., SUDDLE, K., et al. (2006). Los emprendedores con potencial de crecimiento y el desarrollo económico. Políticas de apoyo a los emprendedores. Ekonomiaz, 62(2), 124-149.

URIBE, j. \& DE PABLO, J. (2011). "Revisando el emprendedurismo”, Boletín Económico de ICE, 3021, 53-62.

TABARES, S. (2012). La internacionalización de la pyme latinoamericana: referente para el éxito empresarial en Colombia. Revista Ciencias Estratégicas, 20 (27), 119-132.

TIMMONS, J. (1994). New Venture Creation: entrepreneurship for the 21st century, Chicago: Irwin.

TOPA CANTISANO, G \&; PALACí DESCALS, F. (2005). "Proactividad e identidad organizacional : un análisis multigrupo", Revista de Psicología General y Aplicada, 58 (4), 495-504.

VARGAS, J. Martínez, M. y MOJICA, E.(2010). Influencia de la orientación al mercado y la innovación en la internacionalización y el desempeño de las pymes en el Estado de Aguascalientes. Revista da Micro e Pequeña Empresa.

VERDUGO ROJAS, M.T.(2004). “Una visión proactiva: la agenda modernizadora del Estado Chileno”, Revista Enfoques, 2, 13-24.

VERGANTI, R. (2009). Design - Driven Innovation. Boston, Massachusetts: Harvard Business School Publishing Corporation.

VILADÁS, X. (2010). El Diseño a su Servicio. Barcelona: Index Book S.L.

VOS E., B (1999). El surgimiento del paradigma industrializador en Chile, (1875-1900). Santiago: DIBAM.

\section{Listado de Sitios Web}

Asociación de Emprendedores de Chile (2016). Recuperado de www.asech.cl/

Chile Atiende PYMEs 92016). Recuperado de https://www.chileatiende.gob.cl/empresas

Emprendedores - ideas de negocios, directorio de PYMEs (2016). Recuperado de www.emprendedores.cl/

Estatuto PYME (Ley 20.416). Recuperado de http://www.economia.gob.cl/areas-de-trabajo/subs-economia/ emprendimiento-y-PYMEs/ley-20-416

Innovación (2013). Recuperado de http://www.innovacion.gob.cl/entrevista/el-ecosistema-innovadore-chileno-esta-enetapa-de-transicion/.2013

70 Casos de Innovación - CORFO (2007). Recuperado de www.corfo.cl/

Radiografía de la PYME Industrial - ASIMET (2013). Recuperado de http://www.asimet.cl/estudios articulos.htm.

Evaluación de las relaciones comerciales entre chile y china a siete años de la entrada en vigencia del tratado de libre comercio - DIRECON Estudios Económicos /Ministerio de Relaciones Exteriores de Chile (2013). Recuperado de http:// www.sice.oas.org/TPD/CHL CHN/Studies/FTAreview sept13 s.pdf 


\section{TEXTOS DE REFERENCIA DE LAS IMÁGENES}

Gráfico 1. Guía esquemática del Discurso sobre la Gestión de la Idea (Finizio, 2002).

Gráfico 2. Índice y producción de ventas físicas (INE, 2013).

Gráfico 3. Dimensiones MESO en la pyme manufacturera chilena.

Gráfico 4. Aportes en innovación de empresas chilenas (Ministerio de Economía, 2013).

Gráfico 5. Séptima Encuesta de Innovación en Chile (2015).

Gráfico 6. Novena Encuesta de Innovación MINECOM (2013 - 2014).

Gráfico 7. Cuatro Resultados del Proceso de Innovación design - driven en pymes. 